\title{
Repellent Activity of Essential Oils from Cananga odorata Lamk. and Cymbopogon nardus L. on Corn Starch-Based Thixogel
}

\author{
Nasrul Wathoni 1,2*, Sriwidodo', Ferry Ferdiansyah Sofian², Angga Cipta Narsa ${ }^{3,4}$, Ajeng Ninda Mutiara ${ }^{1}$ \\ 'Department of Pharmaceutics and Pharmaceutical Technology, Faculty of Pharmacy, Universitas Padjajaran, Jatinangor 45363, INDONESIA. \\ ${ }^{2}$ Department of Biology Pharmacy, Faculty of Pharmacy, Universitas Padjadjaran, Jatinangor 45363, INDONESIA. \\ ${ }^{3}$ Research Group of Pharmaceutics, Faculty of Pharmacy, Universitas Mulawarman, Samarinda 75119, INDONESIA. \\ ${ }^{4}$ Scientific Consortium of Drug Discovery and Development, Universitas Padjadjaran, Jatinangor 45363, INDONESIA
}

\begin{abstract}
Objective: The main objective of the research work was to fabricate and characterize the thixogel formulations based on corn starch containing the combination of the essential oils from ylang-ylang (Cananga odorata Lamk.) and citronella (Cymbopogon nardus L.) plants. Then, we investigated their safety consideration, and mosquito repellent activities. Methods: Corn starch based thixogel was prepared by modified method of thixotropic emulsion. The thixotropic properties were measured by comparing the viscosity of the thixogels before and after shaking treatment on selected days during storage for 56 days. Study of skin irritation for thixogel application on human skin was conducted for three consecutive days with modified patch test method. Female Aedes aegypti mosquitoes (3-5 days old) were used in mosquito repellent studies. Results :The organoleptic studies showed that the formulations of thixogel without the essential oils (F0), ylang oils 2\% (F1), citronella oils 2\% (F2), and ylang oils 2\% + citronella oils $2 \%$ (F3) were stable during storage for 56 days. In addition, the viscosity, and irritation skin studies confirmed that all formulas had a thixotropic properties, and without any irritation on human skin. Furthermore, the combination of ylang and citronella oils on corn starch-based thixogel (F3) significantly improved repellant activity against Aedes aegypti compared to its single essential oils on corn starch-based thixogel (F1 and F2). Conclusion: These results suggest that corn starch-based thixogel is
\end{abstract}

promising technology for topical administration of the essential oils as repellent agents, which are safe for humans, domestic animals and friendly.

Key words: Aedes aegypti, Citronella, Essential oil, Thixogel, Mosquito repellent, Ylang-ylang.

Key message:

- Corn starch based thixogel was successfully prepared by modified method of thixotropic emulsion with a good physical stability and a safe formulation for human.

- The combination of ylang and citronella oils on corn starch-based thixogel significantly improved repellant activity against Aedes aegypti compared to its single essential oils on corn starch-based thixogel.

- Corn starch-based thixogel is promising technology for topical administration of the essential oils as repellent agents.

Correspondence

Nasrul Wathoni, Department of Pharmaceutics and Pharmaceutical Technology,

Faculty of Pharmacy, Universitas Padjajaran, Jatinangor 45363, INDONESIA.

Phone: +622284288888

Email: nasrul@unpad.ac.id

DOI: 10.5530/jyp.2018.2s.24

\section{INTRODUCTION}

Aedes aegypti is a mosquito that can spread dengue and other vectorborne diseases such as chikungunya and zika. ${ }^{1}$ The numbers of dengue cases are very high with approximately 2.5 billion people are at risk and 50 million infections occur annually. ${ }^{2}$ Nowadays, to protect skin from the bites of Aedes aegypti, mosquito repellents are commonly used. However, most of the mosquito repellent formulas on the market contain toxic compounds, such as DEET ( $\mathrm{N}, \mathrm{N}$-diethyl-m-toluamide) and Piperonylbutoxide (PBO). ${ }^{3-4}$

Recently, to avoid the side effects of toxic compounds, the essential oils from the plants can be used as a potent mosquito repellent, ${ }^{5}$ including the essential oil from ylang-ylang (Cananga odorata) and citronella (Cymbopogon nardus). Ylang oil is an essential oil produced by Cananga odorata flowers. The largest oil content in ylang flower is linalool and eugenol which cause a distinctive aroma for mosquitoes. ${ }^{6}$ Study has discovered that the ylang oil may act as a potential mosquito egg control agent against Aedes aegypti. ${ }^{7}$ In addition, the essential oil of citronella leaves contains citronella and geraniol which are toxic to kill mosquitoes. ${ }^{8}$ Therefore, we hypothesized that the combination of ylang oil and citronella oil may have a synergistic effect in repellent activity against Aedes aegypti. However, the essential oils are limited for the application due to highly unstable, volatile, and insoluble in water. ${ }^{9-10}$

Thixogel, a unique thixotropic gel properties which can be liquid when stirred or shaken, has been developed as a novel gel formulation for topical drug delivery, especially for hydrophobic plant actives. ${ }^{11}$ The thixogel technology has many advantages, such as a soft oil-in-water emulsion, a quick drying emulsion on the skin, a stable emulsion without the addition of surfactants that can irritate the skin, such as alcohols and fatty acid esters. In addition, it can be used for rough and dry skin. ${ }^{12}$

In general, starch can be used as base formulation of thixogel..$^{13}$ The main requirements of starch for thixogel formulation are a natural polymer of plants, a good water phase with thixotropic properties, an ability to bind and coat oil phase, a very thin transparent layer as a protective skin, and a stable hydrocolloid gel emulsion in combination with both natural and synthetic materials. ${ }^{14-15}(11)$ One of natural starches that has all of these requirements is corn starch.

Therefore, in this study, we fabricated and characterized the thixogel formulations based on corn starch containing the combination of the essential oils from ylang-ylang and citronella plants. Then, we investigated their safety consideration and mosquito repellent activities.

This is an open access article distributed under the terms of the Creative Commons Attribution-NonCommercial-ShareAlike 4.0 License, which allows others to remix, tweak, and build upon the work non-commercially, as long as the author is credited and the new creations are licensed under the identical terms. 


\section{MATERIALS AND METHODS}

\section{Materials}

The essential oil of ylang-ylang (Cananga odorata) and citronella (Cymbopogon nardus) (Lansida Herbal Technology, Yogyakarta, Indonesia), corn starch (Brataco Chemical, Jakarta, Indonesia), and ACNEBIO (propyl P-Hydroxybenzoate, Methyl P-Hydroxybenzoate, bronopol, phenoxyethanol) (Brataco Chemical, Jakarta, Indonesia).All other reagents and chemicals were of analytical grade and used without any further purification.

\section{Animals and Humans}

Female Aedes aegypti mosquitoes (3-5 days old) were used in mosquito repellent studies and granted by Loka Research and Development for Eradication of Disease from Animal (Loka Litbang P2B2, Ciamis, Indonesia). 10 adult of human volunteers were observed for irritation skin test. All the animal and human research studies were approved by the Health Research Ethics Committee Faculty of Medicine, Universitas Padjadjaran, Bandung (Ethical Approval Number: 609/UN.6.C2.1.2/ KEPK/PN/2014).

\section{Fabrication of Corn Starch-Based Thixogel Containing Essential Oils}

Corn starch based thixogel was prepared by modified method of thixotropic emulsion. ${ }^{14}$ Briefly, corn starch-based thixogel were prepared in four formulations (the formulations of thixogel without the essential oils (F0), ylang oils 2\% (F1), citronella oils 2\% (F2), and ylang oils $2 \%+$ citronella oils $2 \%(\mathrm{~F} 3)$. All compositions were prepared and weighed carefully (Table 1). The essential oils and propylene glycol as oil phase was heated at a constant temperature of $50^{\circ} \mathrm{C}$ for $5 \mathrm{~min}$. Corn starch was mixed with sodium lauryl sulfate in distilled water, followed by heating and stirring until the starch solution reached the gelatinization process at boiling point of $90^{\circ} \mathrm{C}$. Then, it was cooled to a temperature of $50^{\circ} \mathrm{C}$. The oil phase was transferred into the corn starch base at a constant temperature of $50^{\circ} \mathrm{C}$, followed by addition of anti-microbial agent $\left(\mathrm{ACNEBIO}^{\circ}\right)$ and the gel was stirred to obtain a homogeneous thixogel. The thixogels were kept in a tightly sealed container and protected from the light.

Table 1: Formulations of Corn Starch-Based Thixogel containing Essential Oils.

\begin{tabular}{ccccc}
\hline Ingredients & \multicolumn{4}{c}{ Formulations (\%) } \\
\cline { 2 - 5 } & F0 & F1 & F2 & F3 \\
\hline Ylang oil & - & 2 & - & 2 \\
Citronella oil & - & - & 2 & 2 \\
Corn starch & 3,5 & 3,5 & 3,5 & 3,5 \\
Sodium Lauryl Sulfate & 0,5 & 0,5 & 0,5 & 0,5 \\
Propyleneglicol & 1,0 & 1,0 & 1,0 & 1,0 \\
ACNEBIO $^{\circ}$ & 0,2 & 0,2 & 0,2 & 0,2 \\
Aquadest ad & 100 & 100 & 100 & 100 \\
\hline
\end{tabular}

The oil phase containing the essential oils and propylene glycol was heated and mixed with corn starch aqueous solution which already reached the gelatinization process. Then, the antimicrobial was added and stirred to obtain a homogeneous thixogel.

\section{Stability and Thixotropic Properties Organoleptic}

Organoleptic studies were investigated by observing the changes in shape, color, and odor of corn starch based thixogel containing ylang oils and citronella oils on days 1, 3, 7, and then every week up to 56 days of storage.

\section{$\mathrm{pH}$}

The thixogel preparations were diluted in distilled water (1:10) and directly measured by $\mathrm{pH}$ meter (Metro ohm 744, Herisau, Switzerland) on selected days during storage for 56 days.

\section{Thixotropic and Flow Properties}

The aliquot of thixogel preparations were weighed $(2 \mathrm{~g})$ and analyzed by viscometer (Brookfield Digital Viscometer type DV-II + Pro, Middleboro, USA) using Spindle number 41 (maximum speed of $100 \mathrm{rpm}$ ). The thixotropic properties were measured by comparing the viscosity of the thixogels before and after shaking treatment on selected days during storage for 56 days. The flow properties of the thixogels can be obtained from the value of shear rate and shear stress, then, it can be calculated with following equation: $\mathrm{y}=\mathrm{F} / \mathrm{G}, \mathrm{y}=$ viscosity, $\mathrm{F}=$ shearing stress, $\mathrm{G}=$ rate of shear. ${ }^{16}$

\section{Irritation Skin Test}

Prediction of skin irritation for thixogel application on human skin was conducted for three consecutive days with modified patch test method. ${ }^{17}$ The study was conducted on 10 volunteers on the back side of volunteer hand. The corn starch based thixogels containing essential oil were applied on the right hand and without essential oil were applied on the left hand as a comparison. After $4 \mathrm{~h}$ application, the skins were observed for the possibility of skin irritation. Then, skin reactions were assessed on a scale of 0 to 6 , inaccordance with the criteria $0=$ no reaction, 1 =perceptible erythema, 2 =weak-to-moderate erythema, 3 =distinct erythema, 4 =erythema with popular or edematous reaction, 5 =erythema with vesicular reaction, and $6=$ corrosive reaction (bullae formation necrosis). ${ }^{18}$

\section{Repellent Activity Against Aedes aegypti}

The mosquito repellent study was performed using the method reported by Das et al. with slightly modifications. ${ }^{19}$ Briefly, Aedes aegypty mosquitoes were kept for 2 days in special cage $(30 \times 30 \times 30 \mathrm{~cm})$. The Mosquitoes were grouped randomly into the cage. Each cage contains 25 mosquitoes. Before the test, the mosquitoes were fasting for 1 day. The thixogel formulations $(200 \mathrm{mg}$ ) were applied on the ventral part of forearm and inserted into the cage. This repellent tests were also conducted for thixogel without any treatment as control. Observations and calculations were performed at $1,2,3$, and $4 \mathrm{~h}$ to determine the duration of mosquitoes that landed on the forearm. The time was started when the volunteer arm inserted into the cage, and the time was stopped when the mosquito up to the forearm. Then, the protection ability was calculated by using the following equation:

$$
\begin{aligned}
& \Sigma \text { Mosquito landed on control - } \\
& \text { Pr otection Ability (\%) }=\frac{\sum \text { Mosquito landed on thixogels }}{\sum \text { Mosquito landed on control }} \times 100
\end{aligned}
$$

\section{Statistical analysis}

Data are given as the mean \pm S.E. Statistical significance of means for the studies was determined by analysis of variance followed by Scheffe's test. p-Values for significance were set at 0.05 . 


\section{RESULTS}

\section{Fabrication of Corn Starch-Based Thixogel containing Essential Oils}

To overcome the limitations of essential oils in topical applications due to a highly unstable, a volatile, and an insoluble in water, we prepared corn starch-based thixogel by thixotropic emulsion method in four formulas. Firstly, the oil phase containing the essential oils and propylene glycol were heated and mixed with corn starch aqueous solution which already reached the gelatinization process. Then, the antimicrobial was added and stirred to obtain a homogeneous thixogel. As the result, all formulations of the corn starch-based thixogels were white, odorless, and viscous gel (Figure 1).

\section{Stability and Thixotropic Properties}

To examine whether the essential oils on corn starch-based thixogel possesses ideal properties as repellent agents, we investigated its stability and thixotropic properties. The organoleptic study had been done by observing the color, shape, and odor of corn starch-based thixogel during storage for 56 days. The organoleptic study showed that there were no change in the shape, odor, and color of all formulations during storage at room temperature for 56 days (Table 2).

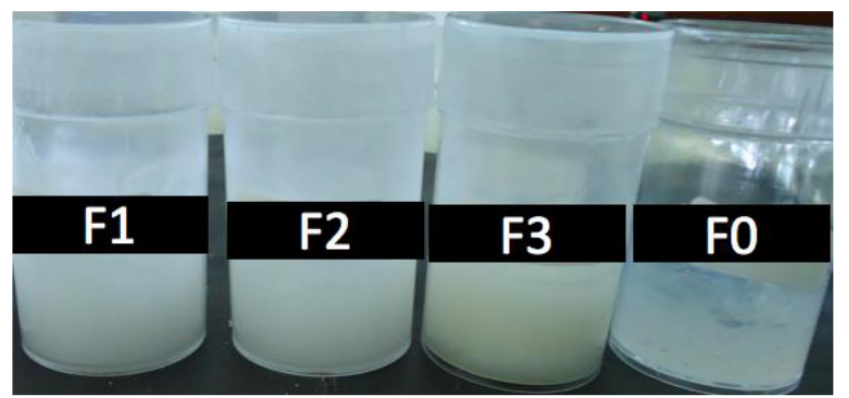

Figure 1: Appearance of Corn Starch-Based Thixogel containing Essential Oils Formulations of thixogel without the essential oils (F0), ylang oil $2 \%$ (F1), citronella oil $2 \%(F 2)$, and ylang oil $2 \%$ + citronella oil $2 \%(F 3)$.

Table 2: Organoleptic Studies of Corn Starch-Based Thixogel containing Essential Oils.

\begin{tabular}{cllllllllllll}
\hline \multirow{2}{*}{ Formulations } & Organoleptics & \multicolumn{10}{c}{ Days } \\
\cline { 2 - 9 } & & 1 & 3 & 7 & 14 & 21 & 28 & 35 & 42 & 49 & 56 \\
\hline \multirow{4}{*}{ F0 } & Shape & - & - & - & - & - & - & - & - & - & - \\
& Color & - & - & - & - & - & - & - & - & - & - \\
& Odor & - & - & - & - & - & - & - & - & - & - \\
& Shape & - & - & - & - & - & - & - & - & - & - \\
& Color & - & - & - & - & - & - & - & - & - & - \\
& Odor & - & - & - & - & - & - & - & - & - & - \\
& F2 & Shape & - & - & - & - & - & - & - & - & - & - \\
& Color & - & - & - & - & - & - & - & - & - & - \\
& Odor & - & - & - & - & - & - & - & - & - & - \\
F3 & Shape & - & - & - & - & - & - & - & - & - & - \\
& Color & - & - & - & - & - & - & - & - & - & - \\
& Odor & - & - & - & - & - & - & - & - & - & - \\
\hline
\end{tabular}

Organoleptic studies were investigated by observing the changes in shape, color, and odor of corn starch based thixogel containing ylang oils and citronella oils on days $1,3,7$, and then every week up to 56 days of storage. (-) no change in organoleptic properties compared to initial day, $(+)$ change in organoleptic properties compared to initial day. Formulations of thixogel without the essential oils (F0), ylang oil $2 \%(\mathrm{~F} 1)$, citronella oil $2 \%(\mathrm{~F} 2)$, and ylang oil $2 \%+$ citronella oil $2 \%(\mathrm{~F} 3)$.
To clarify the stability of the formulation constituents, also their effectiveness and safety as well as be compatible with biological tissues for topical administration, we performed the $\mathrm{pH}$ determination of the essential oils on the corn starch-based thixogel during storage for 56 days. The average $\mathrm{pH}$ values for formulations containing the essential oils showed no significant different compared to control, suggesting that formulations feature reasonable physicochemical stability when subjected to storage for 56 days at room temperature (Figure 2). However, the evaluation during 56 days showed a significant decrease in $\mathrm{pH}$ of all formulations containing the essential oils.

Next, to confirm the essential oils on corn starch-based thixogel has a thixotropic properties, we measured the viscosity of the thixogels. The thixotropic properties were measured by comparing the viscosity of thixogels before and after shaking treatment on selected days during storage for 56 days. The results showed that the viscosity of the thixogels after shaking had a value smaller than the viscosity of the thixogels prior to the shaking (Figure 3), suggesting that the thixogels has a thixotropic properties.

\section{Irritation Skin Test}

Topical administration of the essential oils on corn starch-based thixogel need to be safe for the application. To predict skin irritation caused by topical drug formulations, patch test method in human arm can be done..$^{20}$ In this study, the patch test was performed on 10 volunteers using corn starch-based thixogel containing the combination of ylang and citronella oils (F3) compared to control (F0). Then, skin reactions were assessed on a scale of 0 to 6 , in accordance with the criteria Kawai et al. The results of patch test revealed that no irritation occurred not only in F3 but also in F0 (Table 3), suggesting that corn starch was suitable for the essential oils as a base in the hydrophilic thixogel and it can decrease the irritant ability of sodium lauryl sulfate.

\section{Repellent Activity against Aedes aegypti}

To clarify the repellent activity of ylang and citronella oils against Aedes aegypti on corn starch-based thixogel, we evaluated the mosquito repellent activity. Briefly, Aedes aegypti mosquitoes were kept for 2 days and

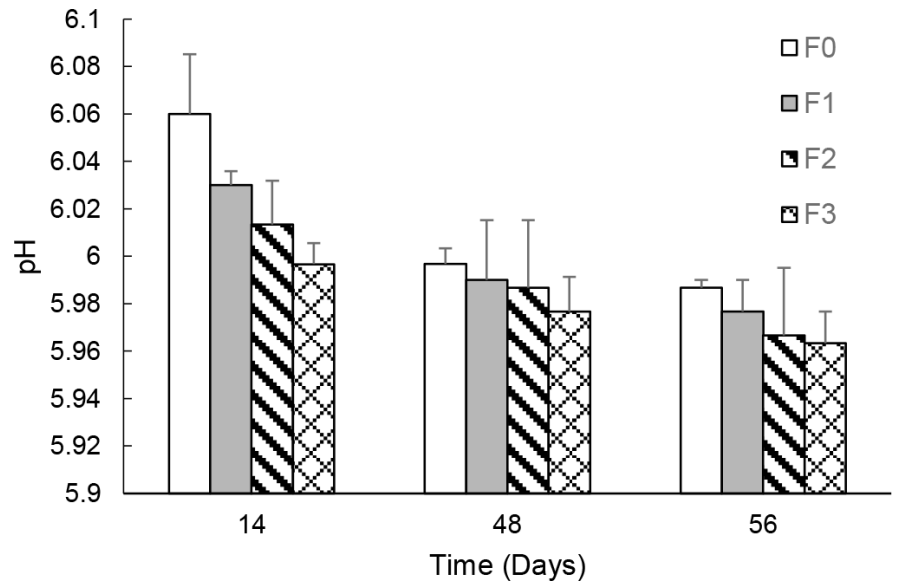

Figure 2: pH Determination of Essential Oils on Corn Starch-based Thixogel.

The thixogel preparations were diluted in distilled water (1:10) and directly measured by pH meter (Metroohm 744, Herisau, Switzerland) on selected days during storage for 56 days. Formulations of thixogel without the essential oils (F0), ylang oil 2\% (F1), citronella oil 2\% (F2), and ylang oils $2 \%+$ citronella oils $2 \%$ (F3). Value are mean \pm standard error of the mean (S.E.M.) of three experiments. 


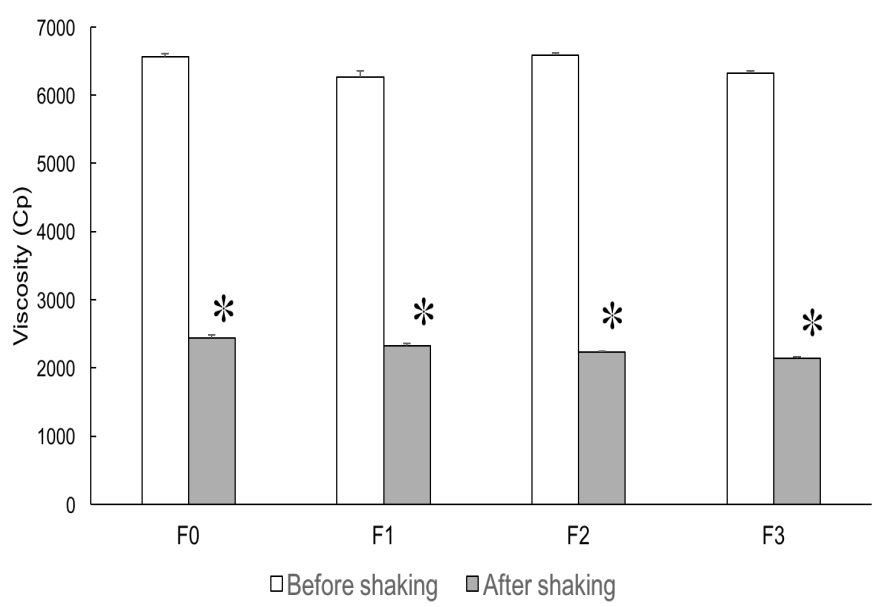

Figure 3: Thixotropic Properties of Corn Starch-Based Thixogel containing Essential Oils.

The thixotropic properties were measured by comparing the viscosity of thixogels before and after shaking treatment on selected days during storage for 56 days. Formulations of thixogel without the essential oils (F0), ylang oil $2 \%$ (F1), citronella oil $2 \%$ (F2), and ylang oil $2 \%+$ citronella oil $2 \%$ (F3). Value are mean \pm standard error of the mean (S.E.M.) of three experiments; ${ }^{*} p<0.05$ compared to before shaking.

Table 3: Patch Irritation Test of Corn Starch-Based Thixogel containing Essential Oils.

\begin{tabular}{ccccccccccc}
\hline \multirow{2}{*}{ Formulations } & \multicolumn{10}{c}{ Volunteers } \\
\cline { 2 - 13 } & A & B & C & D & E & F & G & H & I & J \\
\hline F0 & 0 & 0 & 0 & 0 & 0 & 0 & 0 & 0 & 0 & 0 \\
F3 & 0 & 0 & 0 & 0 & 0 & 0 & 0 & 0 & 0 & 0 \\
\hline
\end{tabular}

The patch irritation test was performed on 10 volunteers using corn starch-based thixogel containing the combination of ylang oil $2 \%+$ citronella oil $2 \%(F 3)$ compared to control without the essential oils (F0).

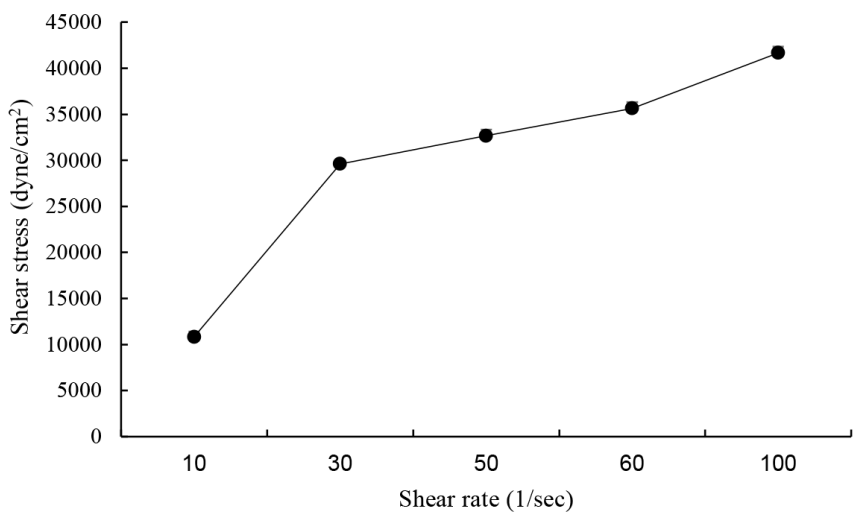

Figure 4: Pseudoplastic Flow of Corn Starch-Based Thixogel containing Essential Oils.

From the viscosity value obtained, it can be calculated the value of shear rate and shear stress with following equation: $\eta=F / G, \eta=$ viscosity, $F=$ shearing stress, $\mathrm{G}=$ rate of shear. Value are mean \pm standard error of the mean (S.E.M.) of three experiments.
A.
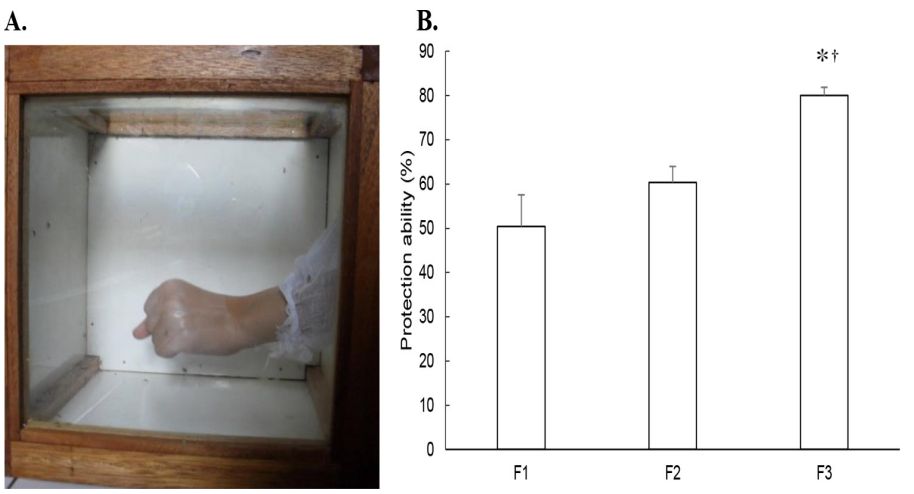

Figure 5: Repellent Activity against Aedes aegypti of Corn Starch-Based Thixogel containing Essential Oils (a) Picture of Repellent Activity Study (b) Protection Ability against Aedes aegypti of the Thixogel Formulations. Aedes aegypti mosquitoes were kept for 2 days and grouped randomly in special cage. The thixogels were applied on the ventral part of forearm and inserted into the cage. Observations and calculations were performed to determine the duration of mosquitoes that landed on the forearm. Value are mean \pm standard error of the mean (S.E.M.) of three experiments; ${ }^{*} p<0.05$ and $\mathrm{tp}<0.05$ compared to $\mathrm{F} 1$ and $\mathrm{F} 2$, respectively.

grouped randomly in special cage. The thixogels were applied on the ventral part of forearm and inserted into the cage. Observations and calculations were performed to determine the duration of mosquitoes that landed on the forearm. As shown in Figure 5, the combination of ylang and citronella oils on corn starch-based thixogel (F3) significantly improved repellant activity against Aedes aegypti compared to its single essential oils on corn starch-based thixogel (F1 and F2), suggesting that the synergistic repellent activity between ylang oil and citronella oil probably occurred on the corn starch-based thixogel.

\section{DISCUSSION}

The gelatinization process in the fabrication of corn starch-based thixogel containing essential oils is important step for decreasing the crystallinity of starch. The gelatinization is a transition process for the granules of starch which decompose into a mixture of d-glucopyranose-based polymers in solution. ${ }^{21-22}$ The starch become more mobile and easier to interact with the essential oils as oil phase. Moreover, sodium lauryl sulfate as surfactant in corn starch solution can decrease the surface tension between water and oil phases. ${ }^{23}$

The preservative used in the corn starch based thixogels is ACNEBIO ${ }^{\circ}$. ACNEBIO $^{\circ}$ is a preservative that contains a mixture of phenoxyetanol, methylparaben, propyl paraben, and bronopol that effectively inhibit gram-negative bacteria, gram-positive bacteria, and fungi. These preservatives are widely used in cosmetic preparations due to their neutral, non-irritating, non-toxic and safe to use. ${ }^{24-26}$

The organoleptic study showed that there were no change in the shape, odor, and color of all formulations during storage at room temperature for 56 days. These result suggest that the essential oils were stable on corn starch-based thixogel, probably due to steady emulsion system in the corn starch-based thixogel. Thixogel is a hydrocolloid emulsion with an oil-in-water emulsion system. ${ }^{11}$

The evaluation during storage showed a significant reduction in $\mathrm{pH}$ value of all formulations containing the essential oils. This observation may reflect the oil phase oxidation phenomenon by the hydrolysis of triglycerides with the formation of fatty acids, responsible for the $\mathrm{pH}$ decrease of the formulations. ${ }^{27-29}$ 
The evaluation of viscosity helps not only to understand the thixotropic properties but also to conclude whether a product provides proper consistency and can indicate if stability is sufficient. (30) It means when sufficiently stirred, it will form a pourable preparation. We further selected F3 which contains ylang oil and citronella oil for the shear viscosity measurements. The results confirmed that F3 exhibited pseudoplastic flow or the viscosity decreasing with increasing applied shear stress (Figure 4). The thixogels has a thixotropic properties which is required in pharmaceutical formulations for avoiding the mobility of the dispersed phase under low shear stress, being important that it exhibits free flow when shaken, showing low viscosity compared to high shear rates, these being reversible changes after certain time repose, delaying coalescence or creaming. ${ }^{30}$

The formulation containing combination of essential oils was selected for skin irritation study because it is assumed that skin irritation may occur such as itching or redness due to optimum concentration of the essential oils. In addition, sodium lauryl sulfate, a well-known irritant, was used as surfactant in the formulation of thixogels. The results of patch test revealed that no irritation occurred not only in F3 but also in F0. These results corroborate the recent study that skin irritation elicited in patch test with sodium lauryl sulfate in hydrophilic cream did not show any irritation. ${ }^{20}(20)$

Finaly, we investigated repellent activity of thixogels against Aedes aegypti. The results showed that the combination of ylang and citronella oils on corn starch-based thixogel (F3) significantly enhanced repellant activity compared to its single essential oils on corn starch-based thixogel (F1 and F2). These results are similar to some previous studies, Das et al. revealed that the synergistic repellent activity of the Curcuma longa, Pogostemon heyneanus and Zanthoxylum limonella essential oils might be useful for developing safer alternatives to synthetic repellents for personal protection against mosquitoes. ${ }^{19}$ In addition, Soonwera et al. confirmed that Cananga odorata oil and Cymbopogon citrates were suitable to be used as green repellents for mosquito control. ${ }^{6}$

\section{CONCLUSION}

In the present study, we successfully fabricated the thixogel formulations based on corn starch containing the combination of the essential oils from ylang-ylang and citronella plants. Importantly, the viscosity, and irritation skin studies confirmed that all formulas had a thixotropic properties, and without any irritation on human skin. Furthermore, the combination of ylang and citronella oils on corn starch-based thixogel (F3) significantly improved repellant activity against Aedes aegypti compared to its single essential oils on corn starch-based thixogel (F1 and F2). These results suggest that corn starch-based thixogel is promising technology for topical administration of the essential oils as repellent agents, which are safe for humans, domestic animals and environmental friendly.

\section{ACKNOWLEDGEMENT}

The authors thank Ministry of Research, Technology and Higher Education, Republic of Indonesia, for providing grant on scientific consortium for drug discovery and development.

\section{CONFLICT OF INTEREST}

The authors have no conflict of interest directly relevant to the content of this article.

\section{ABBREVIATIONS}

n: viscosity; F: shearing stress; G: rate of shear; DEET: N, N-diethyl-mtoluamide; PBO: Piperonylbutoxide; S.E.M: Standard Error of the Mean

\section{REFERENCES}

1. Pliego PE, Velázquez-Castro J, Fraguela CA. Seasonality on the life cycle of Aedes aegypti mosquito and its statistical relation with dengue outbreaks. Appl Math Model. 2017;50:484-96.

2. WHO. Dengue: Guidelines for Diagnosis, Treatment, Prevention and Control, WHO - For research on disease of poverty. 2009.

3. Alpern JD, Dunlop SJ, Dolan BJ, StaufferWM, Boulware DR. Personal Protection Measures Against Mosquitoes, Ticks, and Other Arthropods. Med Clin North Am. 2016;100(2):303-16.

4. Qiu H, Jun HW, McCall JW. Pharmacokinetics, formulation, and safety of insect repellent N,N-diethyl-3-methylbenzamide (deet): A review. J Am Mosq Control Assoc. 1998;14(1):12-27.

5. Pavela R. Essential oils for the development of eco-friendly mosquito larvicides: A review Ind Crops Prod. 2015;76:174-87.

6. Soonwera M. Efficacy of essential oil from Cananga odorata (Lamk.) Hook.f and Thomson (Annonaceae) against three mosquito species Aedes aegypti (L.), Anopheles dirus (Peyton and Harrison), and Culex quinquefasciatus (Say). Parasito Res. 2015;114(12):4531-43.

7. Phasomkusolsil S, Soonwera M. The effects of herbal essential oils on the ovipositiondeterrent and ovicidal activities of Aedes aegypti (Linn.), Anopheles dirus (Peyton and Harrison) and Culex quinquefasciatus (Say). Trop Biomed. 2012;29(1):138-50.

8. Solomon B, Gebre-Mariam T, Asres K. Mosquito Repellent Actions of the Essential Oils of Cymbopogon citratus, Cymbopogon nardus and Eucalyptus citriodora: Evaluation and Formulation Studies. J Essent Oil Bear Plants. 2012;15(5):766-73.

9. Natrajan D, Srinivasan S, Sundar K, Ravindran A. Formulation of essential oil-loaded chitosan-alginate nanocapsules. J Food Drug Anal. 2015;23(3):560-8.

10. Bilia AR, Guccione C, Isacchi B, Righeschi C, Firenzuoli F, Bergonzi MC. Essential Oils Loaded in Nanosystems: A Developing Strategy for a Successful Therapeutic Approach. Evid. Based. Complement. Alternat Med. 2014;2014:1-14.

11. Wille JJ. Thixogel ${ }^{\mathrm{TM}}$ : Novel Topical Delivery Systems for Hydrophobic Plant Actives Delivery System Handbook for Personal Care and Cosmetic Products. William Andrew Publishing. 2005:761-94.

12. Spicer P, Lynch M, Hoath S, Visscher M. Cubosomes ${ }^{\circledR}$ and Self-Assembled Bicontinuous Cubic Liquid Crystalline Phases. Delivery System Handbook for Personal Care and Cosmetic Products. Delivery System Handbook for Personal Care and Cosmetic Products. William Andrew Publishing. 2005:602-60.

13. Djakovic LJ, Sovilj V, Miloševic S. Rheological Behaviour of Thixotropic Starch and Gelatin Gels. Starch - Stärke. 1990;42(90):380-5.

14. Wille Jr JJ. Methods for Preparation of A Thixotropic Microemulsion for Skin Care Formulations. US 20100098734 A1. 2010:1-7.

15. Wathoni N, Sriwidodo, Insani UC. Characterization and optimization of natural maltodextrin-based niosome. J Appl Pharm Sci. 2013;3(7):68-71.

16. Sinko PJ. Martin's Physical Pharmacy and Pharmaceutical Sciences: Physical Chemical and Biopharmaceutical Principles in the Pharmaceutical Sciences. Wolter Kluwers. 2006:533-60.

17. Kanto $H$, Washizaki $K$, Ito M, Matsunaga K, Akamatsu $H$, Kawai $K$, et al. Optimal patch application time in the evaluation of skin irritation. J Dermatol. 2013;40(5):363-9.

18. Kawai K. Proposal of a new standard for skin irritation reaction in patch testing. Vis. Dermatology. 2004;3:74-81.

19. Das NG, Dhiman S, Talukdar PK, Rabha B, Goswami D, Veer V. Synergistic mosquito-repellent activity of Curcuma longa, Pogostemon heyneanus and Zanthoxylum limonella essential oils. J Infect Public Health. 2015;8(4):323-28.

20. Horita K, Horita D, Tomita H, Yasoshima M, Yagami A, Matsunaga K. Effects of different base agents on prediction of skin irritation by sodium lauryl sulfate using patch testing and repeated application test. Toxicology. 2017;382:10-5.

21. Ratnayake WS, Jackson DS. Chapter 5 Starch Gelatinization. Adv Food Nutr Res. 2008;55:221-68.

22. Wathoni N, Motoyama K, Higashi T, Okajima M, Kaneko T, Arima H. Physically crosslinked-sacran hydrogel films for wound dressing application. Int J Biol Macromol. 2016;89:465-70.

23. Nutting GC, Long FA, Harkins WD. The Change with Time of the Surface Tension of Solutions of Sodium Cetyl Sulfate and Sodium Lauryl Sulfate. J Am Chem Soc. 1940;62(6):1496-504

24. Wilson M, Bansal G, Stanley A, Newman HN. Susceptibility of oral bacteria to phenoxyethanol and phenoxyethanol/chlorhexidine combinations. J Periodontol. 1990;61 (8):536-41.

25. Valkova N, Lépine F, Valeanu L, Dupont M, Labrie L, Bisaillon JG, et al. Hydrolysis of 4-Hydroxybenzoic Acid Esters (Parabens) and Their Aerobic Transformation into Phenol by the Resistant Enterobacter cloacae Strain EM. Appl Environ Microbiol. 2001;67(6):2404-9.

26. Shepherd JA, Waigh RD, Gilbert P. Antibacterial action of 2-bromo-2-nitropropane-1,3-diol (bronopol). Antimicrob Agents Chemother. 1988;32(11):1693-8.

27. Barradas TN, Senna JP, Cardoso SA, Nicoli S, Padula C, Santi P, et al. Hydrogel-thickened nanoemulsions based on essential oils for topical delivery of 
psoralen: Permeation and stability studies. Eur J Pharm Biopharm. 2017;116:38-50.

28. Wathoni N, Hasanah AN, Gozali D, WahyuniY, Fauziah LL. Determination of uric acid level by polyaniline and poly (allylamine): Based biosensor. J Adv Pharm Technol Res. 2014;5(1):13-6.

29. Hasanah AN, Wathoni N, Indah RA, Wahyuni Y. Biosensor for uric acid determi- nation based on the combination of polypyrrole and poly (allylamine) films. $J$ Young Pharm. 2014;6(1):39-41.

30. Gupta A, Eral HB, Hatton TA, Doyle PS. Controlling and predicting droplet size of nanoemulsions: Scaling relations with experimental validation. Soft Matter 2016;12(5):1452-8

Article History: Submission Date : 03-01-2018; Revised Date : 12-02-2018; Acceptance Date : 12-03-2018.

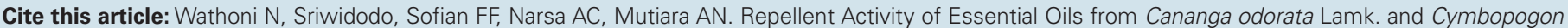
nardus L. on Corn Starch-Based Thixogel. J Young Pharm. 2018;10(2)Suppl:s118-s123. 